\title{
ALTERAÇÕES MORFOFISIOLÓCIAS DE PLANTAS DE ABACAXIZEIRO INFLUENCIADAS POR DIFERENTES SUBSTRATOS DURANTE O PROCESSO DE ACLIMATIZAÇÃO
}

\author{
Morphophysiological changes of pineapple plants influenced \\ by different substrates during the process of acclimatization
}

\author{
Francyane Tavares Braga ${ }^{1}$, Moacir Pasqual ${ }^{2}$, Evaristo Mauro de Castro ${ }^{3}$, Gabriel Coimbra Rafael, \\ Ana Carolina Favero ${ }^{5}$, Thaís Cainã Teixeira Valente ${ }^{4}$
}

\begin{abstract}
RESUMO
Objetivou-se determinar um substrato adequado para aclimatização de plantas micropropagadas de abacaxizeiro 'Gomo de Mel' e a sua caracterização anatômica, durante este processo. $\mathrm{O}$ enraizamento dos brotos foi realizado em meio $\mathrm{MS}$ acrescido de $30 \mathrm{~g} \mathrm{~L}^{-1}$ de sacarose e $6 \mathrm{~g} \mathrm{~L}^{-1}$ de ágar. As culturas foram mantidas em sala de crescimento a $25 \pm 1^{\circ} \mathrm{C}, 36 \mu \mathrm{mol} \mathrm{m}^{-2} \mathrm{~s}^{-1}$ durante 16 horas diárias. Após 60 dias, brotos enraizados foram removidos dos frascos e distribuídos em tubetes, contendo os seguintes tratamentos: 1) $\mathrm{A}+\mathrm{X}+\mathrm{H}(\operatorname{areia}$,

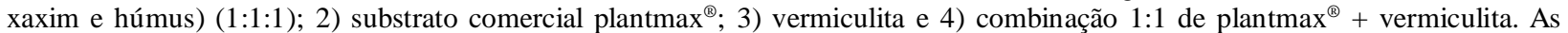
características anatômicas foram avaliadas nas plântulas ainda in vitro e aos 7; 15; 30 e 60 dias de aclimatização. As folhas de transição também foram caracterizadas. $\mathrm{O}$ experimento foi instalado em delineamento inteiramente casualizado, com quatro tratamentos e quatro repetições com cinco plantas. Maiores comprimentos da parte aérea, massa fresca e seca da parte aérea e raízes, foram observados com o uso de areia + xaxim + húmus. Para número de folhas, massa fresca de raízes e massa seca de parte aérea, não houve diferença entre os substratos. Quanto às características anatômicas, o substrato vermiculita, no período de 60 dias de aclimatização, promoveu as maiores espessuras dos tecidos que compõe o limbo foliar.
\end{abstract}

Termos para indexação: Ananas comosus, anatomia vegetal, cultura de tecidos.

\begin{abstract}
This work aimed to determine a right substrate for acclimatization of pineapple 'Gomo de Mel' plantlets and its anatomical characterization during this process. Rooting of the shoots was done in MS medium supplemented with $30 \mathrm{~g} \mathrm{~L}^{-1}$ sucrose and $6 \mathrm{~g} \mathrm{~L}^{-1}$ agar. Cultures were maintained in growth room at $25 \pm 1^{\circ} \mathrm{C}, 36 \mu \mathrm{mol} \mathrm{m} \mathrm{m}^{-2} \mathrm{~s}^{-1}$ during 16 hours. After 60 days, rooted shoots were removed from the bottles and distributed in tubes containing the following treatments: 1) $\mathrm{A}+\mathrm{X}+\mathrm{H}$ (sand, fern tree fiber and humus) (1: 1: 1); 2) commercial substrate Plantmax $^{\circledR}$; 3) vermiculite and 4) 1:1 combination of Plantmax ${ }^{\circledR}+$ Vermiculite. The anatomical characteristics $^{2}$ were evaluated when the seedlings were still in vitro and in the 7th; 15 th; 30 th and 60 th days of acclimatization. The transition leaves were also characterized. The experiment was installed in a randomized completely design, with four treatments and four replicates containing five plants. Higher lengths of roots, fresh and dry mass of roots and roots were observed with the use of sand + fern tree fiber + humus. Leaf number, fresh mass of roots and dry mass of roots did not show differences between substrates. Regarding the anatomical characteristics, the use of vermiculite substrate in the 60 days period of acclimatization promoted the highest thicknesses of the limb tissues.
\end{abstract}

Index terms: Ananas comosus, plant anatomy, tissue culture.

(Recebido em 11 de agosto de 2009 e aprovado em 23 de maio de 2011)

\section{INTRODUÇÃO}

O processo de aclimatização envolve a transferência da planta da condição in vitro para casa de vegetação. Essa passagem é crítica e representa em alguns casos, um fator limitante do processo de micropropagação. Plantas que se desenvolveram heterotroficamente in vitro sob condições de alta umidade passam a condições autotróficas de moderada ou baixa umidade, durante a aclimatização. Em razão da grande diferença entre os dois ambientes, é necessário que plantas micropropagadas passem por esse período de aclimatização antes da transferência para condições de campo (MOREIRA et al., 2007).

\footnotetext{
${ }^{1}$ Universidade do Estado da Bahia/UNEB - Departamento de Educação/DEDC - Paulo Afonso, BA

'Universidade Ferderal de Lavras/UFLA - Departamento de Agricultura/DAG - Lavras, MG

33niversidade Ferderal de Lavras/UFLA - Departamento de Biologia/DBI - Câmpus Universitário - Cx. P. 3037 - $37200-000$ - Lavras, MG emcastro@ufla.br

${ }^{4}$ Universidade Ferderal de Lavras/UFLA - Lavras, MG

${ }^{5}$ Empresa de Pesquisa Agropecuária de Minas Gerais/EPAMIG Uva e Vinho - Caldas, MG
}

Ciênc. agrotec., Lavras, v. 35, n. 5, p. 863-868, set./out., 2011 
Alguns fatores do processo de aclimatização estão diretamente relacionados e, dentre os mais importantes, estão a manutenção da umidade relativa alta dentro da casa de vegetação, as condições de sombreamento, o uso adequado de recipientes e substrato.

O substrato de transplantio deve ter boa capacidade de retenção de umidade e não compactar excessivamente, comprometendo a drenagem e a aeração radicular. Quimicamente ele deve ser de preferência inerte, para permitir a manipulação dos conteúdos de nutrientes, de acordo com a necessidade da espécie (SOUZA JÚNIOR et al., 2001).

O estresse hídrico das plantas é geralmente o maior problema durante o processo de aclimatização. Uma planta, embora aparentemente perfeita in vitro, apresenta deficiências anatômicas que dificultam o controle da transpiração, induzindo a uma rápida perda de água (BARBOZA et al., 2006).

Os estômatos, nesses casos, não são funcionais e respondem muito lentamente ao estresse hídrico, a cera epicuticular é delgada ou inexistente, a conexão vascular entre caule e raízes adventícias é precária para atender à demanda evapotranspiratória (TORRES et al., 2001). Portanto, torna-se importante caracterizar anatomicamente uma planta tanto em condições in vitro, como durante o processo de aclimatização, bem como, escolher adequadamente o substrato, para que possa atender a essa demanda hídrica da planta transplantada.

Neste trabalho, objetivou-se determinar um substrato adequado para as plantas micropropagadas de abacaxizeiro 'Gomo de Mel' por meio da caracterização morfofisiológica das mesmas durante o processo de aclimatização.

\section{MATERIAL E MÉTODOS}

O material vegetal utilizado de abacaxi encontravase já estabelecido in vitro em meio MS (MURASHIGE; SKOOG, 1962) líquido, suplementado com $30 \mathrm{~g} \mathrm{~L}^{-1} \mathrm{de}$ sacarose e $2 \mathrm{mg} \mathrm{L}^{-1}$ de BAP (6-Benzilaminopurina).

Brotos, com aproximadamente $2 \mathrm{~cm}$ de altura, foram selecionados e cultivados em meio MS, acrescido de $6,0 \mathrm{~g} \mathrm{~L}^{-1}$ de ágar para enraizamento. Estes foram mantidos por 60 dias em sala de crescimento a $25 \pm 1^{\circ} \mathrm{Ce} 36 \mu \mathrm{mol} \mathrm{m}^{-2} \mathrm{~s}^{-1}$, durante 16 horas.

Os brotos enraizados foram removidos dos frascos, suas raízes lavadas em água corrente para retirada do meio de cultura e distribuídos em tubetes $(5 \mathrm{~cm}$ de diâmetro $\mathrm{x}$ $24,5 \mathrm{~cm}$ de altura), contendo os seguintes substratos: 1) $\mathrm{A}+\mathrm{X}+\mathrm{H}$ ( areia , xaxim e húmus) (1:1:1);2) substrato comercial plantmax $^{\circledR}$; 3) vermiculita e 4) combinação 1:1 de plantmax ${ }^{\circledR}+$ vermiculita.
Os tubetes contendo as plantas foram levados para casa de vegetação com nebulização intermitente e protegidos com sombrite $50 \%$. As seguintes avaliações fitotécnicas foram realizadas após 60 dias: taxa de sobrevivência, número de folhas, comprimento de parte aérea, massa fresca e seca da parte aérea e das raízes.

A caracterização anatômica foi realizada por meio de: espessura das epidermes adaxial e abaxial, parênquima aqüífero e clorofiliano. Essas avaliações foram realizadas nas plantas ainda in vitro e aos 7; 15; 30 e 60 dias, após aclimatização. As folhas de transição também foram caracterizadas. Para isso, utilizou-se a metodologia descrita por Kraus e Arduin (1997), utilizando-se o terço médio da segunda folha completamente expandida, coletadas de cinco plantas diferentes por tratamento, previamente fixadas em FAA 70\% (formaldeído - ácido acético glacial álcool etílico 70\%) (JOHANSEN, 1940) por 72 horas e, posteriormente, conservadas em etanol $70 \%\left(\mathrm{v} \mathrm{v} \mathrm{v}^{-1}\right)$. As secções transversais foram obtidas em micrótomo de mesa tipo LPC, posteriormente submetidos à clarificação com hipoclorito de sódio (1-1,25\% de cloro ativo), tríplice lavagem em água destilada, coloração com solução safrablau (azul de astra $0,1 \%$ e safranina $1 \%$ ), as lâminas semipermanentes foram montadas com água glicerinada.

O delineamento utilizado foi o inteiramente casualizado com quatro repetições e cinco plantas cada. Os dados foram submetidos à análise de variância, onde as médias foram comparadas pelo Teste de Tukey a $5 \%$ de probabilidade. As análises estatísticas foram realizadas, utilizando o software Sisvar 5.0 (FERREIRA, 2000).

\section{RESULTADOS E DISCUSSÃO}

A taxa de sobrevivência das plantas para os tratamentos Plantmax, Vermiculita e Plantmax + Vermiculita foi de $100 \%$, porém, para o tratamento areia $(\mathrm{A})+\operatorname{xaxim}(\mathrm{X})+$ húmus $(\mathrm{H})$ apenas $60 \%$ das plantas sobreviveram. As plantas desse tratamento morreram, em decorrência de possível contaminação, supostamente presente nesse substrato, causando nas folhas podridão e amarelecimento, levando as mesmas a murcha e consequente morte.

Melhores resultados foram observados para as variáveis comprimento e massa fresca de parte aérea e massa seca de raízes, onde, $\mathrm{A}+\mathrm{X}+\mathrm{H}$ apresentou maiores resultados para as duas primeiras variáveis, já, para massa seca de raízes $\mathrm{A}+\mathrm{X}+\mathrm{H}$, Plantmax ${ }^{\circledR}$ e Plantmax ${ }^{\circledR}+$ Vermiculita apresentaram maiores médias, não diferindo estatisticamente entre si (Tabela 1). Esses resultados corroboram aqueles obtidos por Souza Júnior et al. (2001) onde verificaram que o uso de $\mathrm{A}+\mathrm{X}+\mathrm{H}$ e $\mathrm{Plantmax}^{\circledR}$ foram substratos eficientes na aclimatização de plantas de abacaxi cv. Pérola micropropagadas. 
Número de folhas, massa fresca de raízes e massa seca de parte aérea não apresentaram diferenças significativas entre os substratos avaliados.

Partindo do princípio de que mudas de abacaxizeiro micropropagadas têm um período de seis a oito meses de aclimatização, a escolha correta do substrato e uma adequada adubação durante esse processo, pode favorecer seu crescimento e desenvolvimento, podendo, antecipar o transplantio para o campo (TEIXEIRA et al., 2001). Algumas variáveis analisadas permitem, em muitos casos, definir o momento certo para realizar essa transferência da casa de vegetação para o campo. Dentre elas, altura da muda e número de folhas e raízes são importantes parâmetros para designar essa mudança.

Folhas de abacaxizeiro na fase in vitro apresentam epidermes unisseriadas, estômatos apenas na superfície abaxial das folhas (hipostomática), parênquimas aquífero e clorofiliano pouco desenvolvidos e desorganizados, tricomas glandulares e tectores e fibras ao longo do parênquima clorofiliano (Figura 1).

Quanto às características do mesofilo de folhas na fase in vitro, apresentam parênquima aquífero, constituído por células grandes e parênquima clorofilado com células arredondadas.

Observou-se, também, que a cutícula é pouco desenvolvida nas faces adaxial e abaxial da epiderme. A presença de tricomas nas folhas de abacaxizeiro tanto na fase in vitro quanto durante o processo de aclimatização é uma característica que também foi observada por Barboza et al. (2006) e Silva et al. (2008). Tais estruturas podem representar adaptação morfológica que atua de modo a restringir a perda de água pelas folhas, por meio da regulação da temperatura e reflexão da luz que chega às folhas, e pode, ainda, secretar substâncias que protegem as folhas contra parasitas e predadores (LARCHER, 2000). Essas características são importantes para prevenir a excessiva perda de água na aclimatização, sendo essa a principal causa de morte das plantas durante esse processo.
No sétimo dia de aclimatização o parênquima aquífero de folhas oriundas dos tratamentos com substrato plantmax, plantmax+vermiculita e $\mathrm{A}+\mathrm{X}+\mathrm{H}$, apresentou-se pouco desenvolvido e com células pequenas e achatadas, assim como, nas folhas in vitro (Figura 1). Para todos os tratamentos houve pouca diferenciação dos tecidos até o décimo quinto dia, demonstrando que maior diferenciação ocorreu somente a partir do trigésimo dia de aclimatização e maior deposição de cera na epiderme das folhas a partir desse período. Essas folhas podem ser denominadas primordiais in vitro, por assumirem características intermediárias entre folhas crescidas durante o processo in vitro e de aclimatização (SOARES, 2005).

Por outro lado, folhas de transição são folhas novas produzidas durante o período de aclimatização. Segundo Dignart et al. (2009), essas folhas podem conferir maior capacidade fotossintética, consequentemente aquisição de fotoautotrofia e de regulação hídrica às plantas. Foram observadas diferenças marcantes com relação a essas folhas, onde, os tecidos do mesofilo apresentaram-se uniformes para todos os tratamentos, com maior espessura do parênquima clorofiliano em relação ao aquífero, confirmando maior capacidade fotossintética, vasos de xilema e floema mais desenvolvidos e também maior deposição de cera epicuticular, conferindo assim, maior proteção e controle na perda de água (Figura 1).

Quanto às espessuras dos tecidos que compõem o limbo foliar, foram observadas diferenças estatísticas para interação substrato e tempo de aclimatização (Tabela 2).

Plantas com 60 dias de aclimatização em substrato vermiculita, mostraram as maiores espessuras para todos os tecidos do limbo foliar. Os resultados apresentados quanto ao tempo de aclimatização, eram esperados, uma vez que, houve aumento crescente das espessuras dos tecidos no decorrer do período.

Apesar do substrato $\mathrm{A}+\mathrm{X}+\mathrm{H}$ ter apresentado as maiores médias para as características que avaliam o crescimento, recomenda-se a vermiculita como substrato

Tabela 1 - Número de folhas (NF), comprimento de parte aérea (CPA), massa fresca de parte aérea (MFA), massa fresca de raízes (MFR), massa seca de parte aérea (MSA) e massa seca de raízes (MSR), de abacaxizeiros aclimatizados com diferentes substratos.

\begin{tabular}{ccccccc}
\hline Substrato & NF & CPA $(\mathrm{cm})$ & MFA $\left(\mathrm{g}^{-1}\right)$ & MFR $\left(\mathrm{g}^{-1}\right)$ & MSA $\left(\mathrm{g}^{-1}\right)$ & MSR $\left(\mathrm{g}^{-1}\right)$ \\
\hline A+X+H & $19,8 \mathrm{a}^{*}$ & $9,55 \mathrm{a}$ & $4,31 \mathrm{a}$ & $1,18 \mathrm{a}$ & $0,33 \mathrm{a}$ & $0,088 \mathrm{a}$ \\
Plantmax & $17,1 \mathrm{a}$ & $6,92 \mathrm{~b}$ & $3,27 \mathrm{~b}$ & $1,29 \mathrm{a}$ & $0,26 \mathrm{a}$ & $0,089 \mathrm{a}$ \\
Vermiculita $^{\circledR}$ & $17,6 \mathrm{a}$ & $6,10 \mathrm{~b}$ & $2,85 \mathrm{~b}$ & $0,82 \mathrm{a}$ & $0,22 \mathrm{a}$ & $0,055 \mathrm{~b}$ \\
Plant $^{\circledR}+$ Verm & $18,8 \mathrm{a}$ & $6,75 \mathrm{~b}$ & $3,12 \mathrm{~b}$ & $1,54 \mathrm{a}$ & $0,26 \mathrm{a}$ & $0,124 \mathrm{a}$ \\
\hline
\end{tabular}

*Médias seguidas da mesma letra na coluna não diferem entre si, pelo teste de Tukey a $5 \%$ de probabilidade. 
para aclimatização de abacaxizeiro 'Gomo de Mel'. Essa escolha ocorreu pelas seguintes razões: 1) elevada taxa de mortalidade apresentada no substrato $\mathrm{A}+\mathrm{X}+\mathrm{H} ; 2$ ) não houve diferenças significativas em número de folhas, massa fresca de raízes e massa seca de parte aérea; 3) folhas desenvolvidas em substrato vermiculita apresentaram as maiores espessuras de seus tecidos e 4) vermiculita tem custo inferior aos demais substratos.
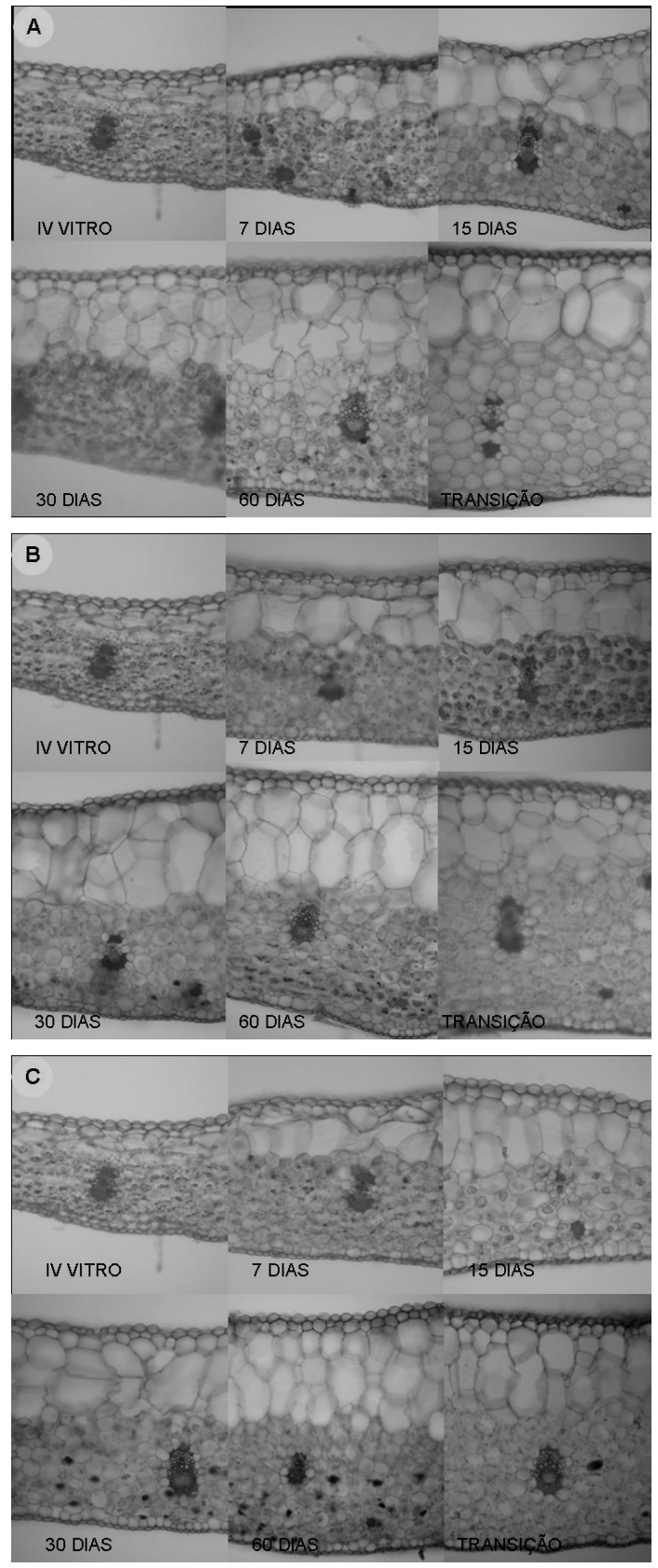

Figura 1 - Fotomicrografias de secções transversais de folhas de abacaxizeiro cultivadas in vitro e aclimatizadas com diferentes substratos e analisada no período de 7; 15; 30 e 60 dias e folhas de transição. (A) plantmax, (B) vermiculita,

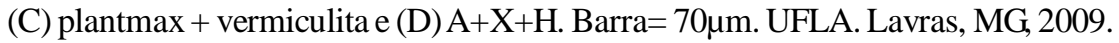

Ciênc. agrotec., Lavras, v. 35, n. 5, p. 863-868, set./out., 2011 
Tabela 2 - Epiderme abaxial e adaxial, parênquima clorofiliano e aquífero de folhas de abacaxizeiro desenvolvidas em diferentes substratos e período de aclimatização.

\begin{tabular}{|c|c|c|c|c|c|c|}
\hline \multirow{3}{*}{ SUBSTRATO } & \multicolumn{6}{|c|}{ PERÍODO DE ACLIMATIZAÇÃO (DIAS) } \\
\hline & \multicolumn{6}{|c|}{ EPIDERME ABAXIAL $(\mu \mathrm{m})$} \\
\hline & 0 & 7 & 15 & 30 & 60 & Transição \\
\hline $\mathrm{A}+\mathrm{X}+\mathrm{H}$ & $25,21 \mathrm{aB}$ & $18,74 \mathrm{aB}$ & $22,76 \mathrm{aB}$ & $18,81 \mathrm{aB}$ & $28,37 \mathrm{bA}$ & $24,37 \mathrm{aB}$ \\
\hline Plan + Verm & $25,21 \mathrm{aB}$ & $16,61 \mathrm{aC}$ & $24,15 \mathrm{aB}$ & $19,84 \mathrm{aC}$ & $38,28 \mathrm{bA}$ & $24,35 \mathrm{bA}$ \\
\hline Plantmax & $25,21 \mathrm{aA}$ & $16,90 \mathrm{aB}$ & $24,94 \mathrm{aA}$ & $15,46 \mathrm{aB}$ & $19,37 \mathrm{cA}$ & $16,88 \mathrm{bB}$ \\
\hline \multirow[t]{2}{*}{ Vermiculita } & $25,21 \mathrm{aB}$ & $17,84 \mathrm{aC}$ & $15,76 \mathrm{bC}$ & $19,86 \mathrm{cA}$ & $39,96 \mathrm{aA}$ & $19,63 \mathrm{bB}$ \\
\hline & \multicolumn{6}{|c|}{ EPIDERME ADAXIAL $(\mu \mathrm{m})$} \\
\hline $\mathrm{A}+\mathrm{X}+\mathrm{H}$ & $16,16 \mathrm{aB}$ & $22,36 \mathrm{aAB}$ & $20,25 \mathrm{abB}$ & $16,93 \mathrm{aB}$ & $28,30 \mathrm{bA}$ & $21,80 \mathrm{aAB}$ \\
\hline Plan + Verm & $16,16 \mathrm{aC}$ & $17,89 \mathrm{abC}$ & $21,36 \mathrm{aBC}$ & $19,62 \mathrm{aBC}$ & $33,63 \mathrm{bA}$ & $25,27 \mathrm{aB}$ \\
\hline Plantmax & $16,16 \mathrm{aB}$ & $16,14 \mathrm{abB}$ & $14,87 \mathrm{bB}$ & $15,76 \mathrm{aB}$ & $14,75 \mathrm{cB}$ & $23,27 \mathrm{aA}$ \\
\hline \multirow[t]{2}{*}{ Vermiculita } & $16,16 \mathrm{aBC}$ & $14,63 \mathrm{bC}$ & $17,11 \mathrm{abBC}$ & $18,51 \mathrm{aBC}$ & $48,03 \mathrm{aA}$ & $22,17 \mathrm{aB}$ \\
\hline & \multicolumn{6}{|c|}{ PARÊNQUIMA CLOROFILIANO $(\mu \mathrm{m})$} \\
\hline $\mathrm{A}+\mathrm{X}+\mathrm{H}$ & $146,78 \mathrm{aC}$ & $144,60 \mathrm{bC}$ & $158,34 \mathrm{bC}$ & $152,77 \mathrm{bC}$ & $308,36 \mathrm{bA}$ & $258,13 \mathrm{bB}$ \\
\hline Plan + Verm & $146,78 \mathrm{aD}$ & $174,75 \mathrm{aC}$ & $185,19 \mathrm{aC}$ & $190,09 \mathrm{aC}$ & $322,90 \mathrm{bA}$ & $258,63 \mathrm{bB}$ \\
\hline Plantmax & $146,78 \mathrm{aD}$ & $136,20 \mathrm{bD}$ & $155,30 \mathrm{bD}$ & $184,30 \mathrm{aC}$ & $220,76 \mathrm{cB}$ & $297,99 \mathrm{aA}$ \\
\hline \multirow[t]{2}{*}{ Vermiculita } & $146,78 \mathrm{aD}$ & $167,76 \mathrm{aD}$ & $151,85 \mathrm{bD}$ & $190,47 \mathrm{aC}$ & $432,36 \mathrm{aA}$ & $291,48 \mathrm{aB}$ \\
\hline & \multicolumn{6}{|c|}{ PARÊNQUIMA AQUÍFERO $(\mu \mathrm{m})$} \\
\hline $\mathrm{A}+\mathrm{X}+\mathrm{H}$ & $103,92 \mathrm{aD}$ & $112,46 b D$ & $186,55 \mathrm{aB}$ & $150,62 \mathrm{bC}$ & $314,32 \mathrm{bA}$ & $159,95 \mathrm{aC}$ \\
\hline Plan + Verm & $103,92 \mathrm{aD}$ & $132,79 \mathrm{aD}$ & $188,55 \mathrm{aB}$ & $185,67 \mathrm{bB}$ & $317,68 \mathrm{bA}$ & $171,27 \mathrm{aBC}$ \\
\hline Plantmax & $103,92 \mathrm{aCD}$ & $74,01 \mathrm{bD}$ & $142,37 \mathrm{cBC}$ & $186,75 \mathrm{aA}$ & $134,56 \mathrm{aA}$ & $168,90 \mathrm{aAB}$ \\
\hline Vermiculita & $103,92 \mathrm{aC}$ & $134,32 \mathrm{aV}$ & $146,26 \mathrm{bBC}$ & $210,66 \mathrm{aB}$ & $383,84 \mathrm{aA}$ & $136,37 \mathrm{aC}$ \\
\hline
\end{tabular}

"Médias seguidas da mesma letra minúscula na coluna e maiúscula na linha não diferem entre si, pelo teste de Tukey a $5 \%$ de probabilidade.

\section{CONCLUSÃO}

Considerando-se a maior espessura dos tecidos do limbo foliar, quando se utiliza a vermiculita, este é o substrato recomendado para aclimatização de abacaxizeiro 'Gomo de Mel'.

\section{AGRADECIMENTOS}

À Fundação de Amparo à Pesquisa do Estado de Minas Gerais, ao Conselho Nacional de Desenvolvimento Científico e Tecnológico e à Coordenação de Aperfeiçoamento de Pessoal de Nível Superior pelo apoio financeiro recebido.

\section{REFERÊNCIAS BIBLIOGRÁFICAS}

BARBOZA, S.B.S.C. et al. Anatomia foliar de plantas micropropagadas de abacaxi. Pesquisa Agropecuária Brasileira, v. 41, p. 185-194, 2006.
DIGNART, S.L. et al. Luz natural e concentrações de sacarose no cultivo in vitro de Cattleya walkeriana.

Ciência e Agrotecnologia, Lavras, v. 33, n. 3, p. 780-787, 2009.

FERREIRA, D.F. SISVAR 5.0: sistema de análise estatística. Lavras: UFLA/DEX, 2000. Software.

KRAUS, J.E.; ARDUIM, M. Manual básico de métodos em morfologia vegetal. Rio de Janeiro: Seropédica, 1997. 198 .

JOHANSEN, D. A. Plant microtechnique. Mc Graw Hill, New York. 523 p. 1940.

LARCHER, W. Ecofisiologia vegetal. RiMa. São Carlos, SP. 531p. 2000. 
MOREIRA, M.A. et al. Respostas à adubação NPK de mudas micropropagadas de abacaxizeiro cv. Pérola em fase de aclimatização. Plant Cell Culture \&

Micropropagation. Lavras, v.3, n.1, p. 17-22, 2007.

MURASHIGE, T.; SKOOG, F. A revised médium for rapid growth and bioassays with tobacco tissue cultures.

Physiologia Plantrarum, v.15, p.473-497, 1962.

SILVA, A.B. da. et al. Luz natural na micropropagação do abacaxizeiro (Ananas comosus L. Merr). Interciencia, v. 33, p.839-843, 2008.

SOARES, F.P. Aspectos do cultivo in vitro da mangabeira (Hancornia speciosa Gomes). 2005. 121p.Dissertação (Mestrado em Agronomia/Fisiologia Vegetal)Universidade Federal de Lavras, Lavras MG.
SOUZA JÚNIOR, E.E.; BARBOZA, S.B.S.C.; SOUZA, L.A.C. Efeitos de substratos e recipientes na aclimatização de plântulas de abacaxizeiro (Ananas comosus L. Merr) cv. Pérola. Pesquisa Agropecuária Tropical, v. 31, n. 2, p. 147-151, 2001.

TEIXEIRA, J.B. et al. Biotecnologia aplicada à produção de mudas: produção de mudas micropropagadas de abacaxi. Biotecnologia, Ciência e Desenvolvimento. Brasília, v.3, p. 42-47, 2001.

TORRES, A. C. et al. Meio e condições de incubação para a cultura de tecidos de plantas: formulações de meio de cultura de tecidos de plantas. 2001. 19 p. (Circular Técnica, 24). 